\title{
КАРБОНАТИТОВЫЕ ПРОВИНЦИИ - ВОПРОСЫ ПРОСТРАНСТВЕННОЙ ОДНОРОДНОСТИ ПЛЮМОВОГО МАГМАТИЗМА, И ЕГО СВЯЗЬ С LІР ПРОВИНЦИЯМИ
}

\section{Асавин А.М., Чесалова Е.И.}

ГЕОХИ РАН, Москва, aalex06@inbox.ru, ГГМ РАН Москва, chesalova_ei@mail.ru

Выделение локальных щелочных провинций во многом связано с представлениями о их образовании в результате долговременной активности крупного мантийного плюма. Следствием такого представления является возможность оценки пространственной зональности химической магматизма провинций. В этой связи представляет интерес хотя бы качественно оценить насколько близка геохимия магматических проявлений в центре провинций и на их границах. Одной из возможностей такой оценки представляет предложенная типизация проявлений карбонатитового магматизма в щелочных массивах мира, выполненная в работах Вулли [3; 4] на основе разработанной ими базы данных «World Carbonatite» [5]. Ими проведена систематическая типизация комплексов щелочных магматических фаз, ассоциирующихся с карбонатитами. Выделено 12 устойчивых ассоциаций. Позднее мы повторили эту работу и несколько детализировали ее, выделив 24 ассоциации [2]. Эти группы-ассоциации можно объединить в более крупные единицы - 10 классов, которые практически соответствуют классам, выделенным Вулли. Результаты представлены в таблице 1, где указано количество массивов, попадающих в каждую из групп. Видно, что результаты достаточно близкие. Отличия отмечены главным образом в детальности выделения петрографических ассоциаций. Отличием предлагаемой типизации является выделение монофазных массивов (М - в табл.), состоящих из 1-2 интрузивных фаз и полифазных массивов (П- в табл.) - 3-х и более типов интрузивных пород. В старых классификациях этот факт не был отмечен. Хотя ряд исследователей щелочноультраосновных провинций обращали на это внимание.

Практически важным результатом данной классификации оказывается возможность оценить однородность магматизма в пределах щелочных провинций и наличие, или отсутствие зональности. На рисунке 1 представлены статистичские круговые диаграммы развития в пределах каждой провинции выделенных классов. Видно, что наряду с моно-провинциями с 2-3 классами присутствуют и мульти-классовые провинции.

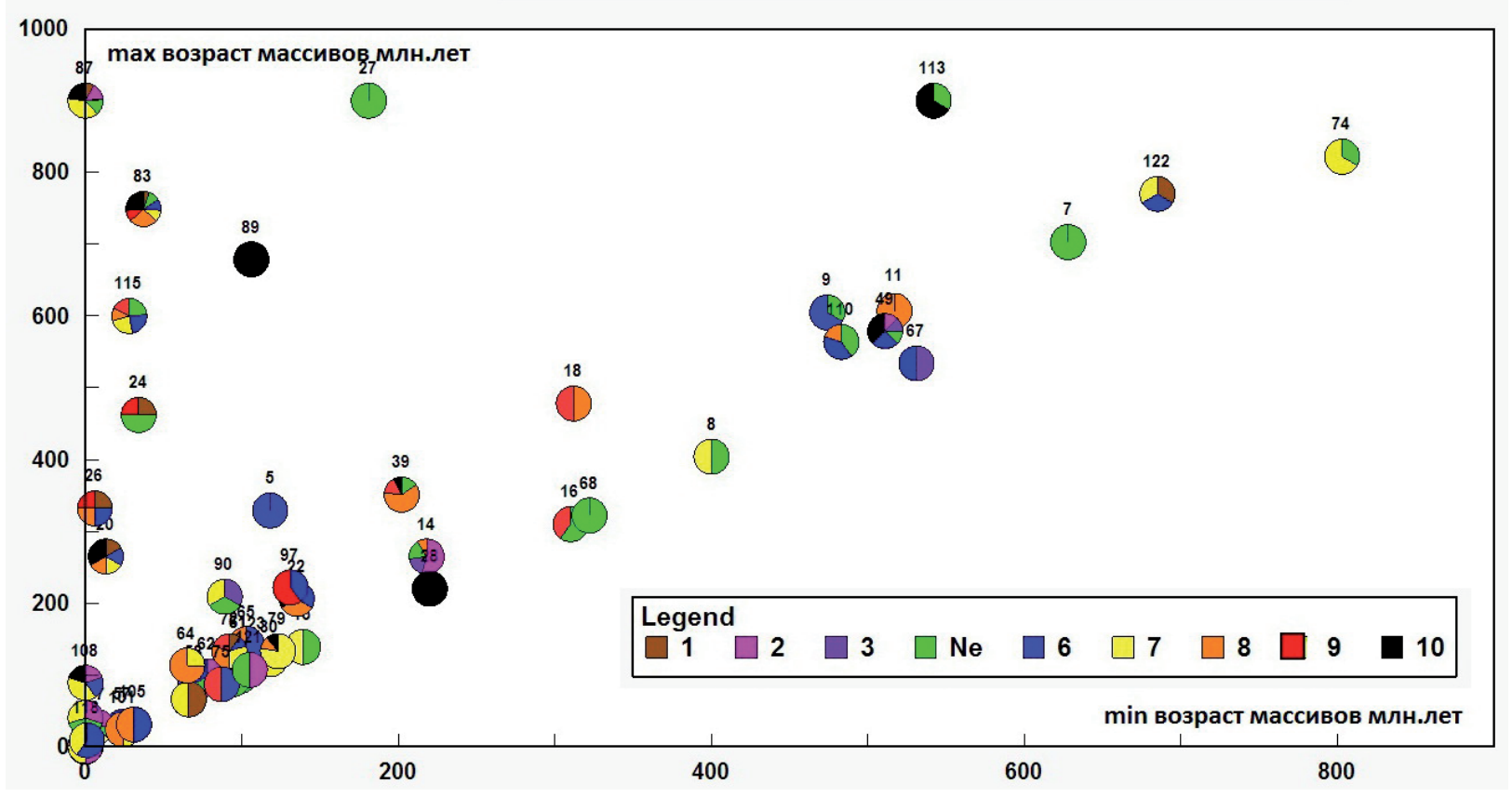

Рис. 1. Круговые диаграммы распространенности разных щелочных ассоциаций в провинциях (номер у кружка соответсвует условному номеру провинции в базе). 
Таблица 1. Соотношения классификаций щелочно-карбонатитовых магматических комплексов на основе плутонических ассоциаций пород (М- моно породная ассоциация;

П - полифазная ассоциация содержащая свыше 3-4 типов пород).

\begin{tabular}{|c|c|c|c|c|c|c|}
\hline $\begin{array}{l}\text { № класса } \\
\text { (кол-во } \\
\text { массивов) }\end{array}$ & 党 & Asavin $2015[2]$ & $\mathbf{n}$ & Классификация [4] & $\mathbf{n}$ & $\begin{array}{c}\text { Боро- } \\
\text { дин и др. } \\
\mathbf{1 9 7 3}[\mathbf{1}]\end{array}$ \\
\hline \multirow{3}{*}{$1(22)$} & 1 & М-дунит-оливинит (перидотит) & 5 & \multirow{3}{*}{$\begin{array}{l}\text { Оливин-пироксеновые } \\
\text { ультраосновные породы }\end{array}$} & \multirow{3}{*}{21} & \multirow{9}{*}{$\begin{array}{l}\text { Щелоч- } \\
\text { но ультра- } \\
\text { основные } \\
\text { породы и } \\
\text { Ne-сиениты }\end{array}$} \\
\hline & 2 & М-перидотит щелочной-глиммерит & 7 & & & \\
\hline & 3 & М-пироксенит & 10 & & & \\
\hline \multirow{4}{*}{$2(30)$} & 4 & $\begin{array}{l}\text { М-мелилитит -(оливиновый } \\
\text { мелилитит)-сиенит }\end{array}$ & 13 & \multirow{3}{*}{ Мелилитолит } & \multirow{3}{*}{16} & \\
\hline & 5 & П-Дунит-перидотит и мелилитолиты & 4 & & & \\
\hline & 6 & $\begin{array}{l}\text { П-Оливинит-Турьяит-Мелилитолит- } \\
\text { мельтейгит- ийолит-Нефелиновый (Ne) } \\
\text { сиенит }\end{array}$ & 7 & & & \\
\hline & 7 & $\begin{array}{l}\text { П-мелилитолиты- мельтейгит- } \\
\text { ийолит-Ne- сиенит }\end{array}$ & 6 & $\begin{array}{l}\text { Мелилитит, мелилит- } \\
\text { нефелиновые интрузив- } \\
\text { ные фазы ( } \pm \text { Мелилитолит) }\end{array}$ & 14 & \\
\hline \multirow[b]{2}{*}{$3(20)$} & 8 & М-Перидотит -Ийолит-Ne-сиенит & 13 & \multirow{2}{*}{$\begin{array}{l}\text { Оливин-пироксеновые } \\
\text { породы и сиенит }\end{array}$} & \multirow[b]{2}{*}{9} & \\
\hline & 9 & $\begin{array}{l}\text { П-Оливинит-пироксенит } \\
\text {-мельтейгит-ийолит }\end{array}$ & 7 & & & \\
\hline \multirow[b]{2}{*}{$4(54)$} & 10 & $\begin{array}{l}\text { П-Пироксенит-Ийолит-Уртит-Ne- } \\
\text { сиенит }\end{array}$ & 20 & Пироксенит и сиенит & 23 & \multirow{8}{*}{$\begin{array}{l}\text { щелочные } \\
\text { габброи- } \\
\text { ды и Ne- } \\
\text { сиениты }\end{array}$} \\
\hline & 11 & $\begin{array}{l}\text { П- (士якупирангит) -мельтейгит- } \\
\text { Ийолит-Уртит-Ne-сиенит-агпаит- } \\
\text { сиенит (фонолит) }\end{array}$ & 34 & $\begin{array}{l}\text { Мельтейгит-Ийолит- } \\
\text { Уртит- (土 ультраоснов- } \\
\text { ные породы, сиенит) }\end{array}$ & 87 & \\
\hline $5(14)$ & 12 & $\begin{array}{l}\text { М- Ийолит-Уртит -Ne-сиенит -ще- } \\
\text { лочной гранит }\end{array}$ & 14 & $\begin{array}{l}\text { Нефелинитовые экстру- } \\
\text { зии (土 M-I-U) }\end{array}$ & 38 & \\
\hline \multirow{5}{*}{$6(56)$} & 13 & $\begin{array}{l}\text { П-Перидотит-Ne-пироксенит-Ийолит- } \\
\text { Уртит- Щелочное габбро-сиенит }\end{array}$ & 7 & \multirow{5}{*}{$\begin{array}{l}\text { Шелочное габбро- } \\
\text { Эссексит -Базанит - } \\
\text { Тефрит }\end{array}$} & \multirow{5}{*}{5} & \\
\hline & 14 & М- Пироксенит- Ийолит-Габбро-сиенит & 12 & & & \\
\hline & 15 & $\begin{array}{l}\text { П- (士якупирангит) -мельтейгит - } \\
\text { Габбро-уртит-сиенит-фонолит }\end{array}$ & 12 & & & \\
\hline & 16 & М- габбро-сиенит-(фонолит) & 22 & & & \\
\hline & 17 & М- Ийолит-щелочное габбро & 3 & & & \\
\hline \multirow{3}{*}{$7(75)$} & 18 & $\begin{array}{l}\text { M- (土Ne-сиенит) -(базанит)- } \\
\text { Нефелиниты-фонолиты-трахиты }\end{array}$ & 42 & $\begin{array}{l}\text { Фонолиты, фелъдшпа- } \\
\text { тоидные Сиениты }\end{array}$ & 68 & $\mathrm{Ne}-$ \\
\hline & 19 & М- Пироксенит-Ne-сиенит & 12 & \multirow{3}{*}{ Пироксенит-Сиениты } & \multirow{3}{*}{23} & и фель- \\
\hline & 20 & $\begin{array}{l}\text { П-Ийолит-Фояит-Агп. Сиенит- } \\
\text { Фонолит }\end{array}$ & 21 & & & $\begin{array}{l}\text { дшпатоид- } \\
\text { ные сие- }\end{array}$ \\
\hline \multirow{2}{*}{$8(61)$} & 21 & M-Ne-сиенит & 38 & & & \\
\hline & 22 & Сиенит-Ne-сиенит-Агп. сиенит & 23 & \multirow{2}{*}{$\begin{array}{l}\text { Трахит, Кварцевый (Q) } \\
\text { трахит, Сиенит, Q- Си- } \\
\text { ениты }\end{array}$} & \multirow[b]{2}{*}{43} & щелочны- \\
\hline \multirow[t]{2}{*}{$9(25)$} & 23 & $\begin{array}{l}\text { П- Ne- сиенит- агп. сиенит - трахиты- } \\
\text { Q-Сиенит- (土граниты) }\end{array}$ & 20 & & & $\begin{array}{l}\text { ми сиени- } \\
\text { ты и гра- } \\
\text { носиениты }\end{array}$ \\
\hline & 24 & М-Гранит-агпаитовые граниты & 5 & & & \\
\hline \multirow[t]{2}{*}{$10(47)$} & 25 & $\begin{array}{l}\text { Линейные Массивы дайкового типа } \\
\text { лампрофиры и щелочные вулканиты } \\
\text { (интрузивные фации неизвестны) }\end{array}$ & 47 & $\begin{array}{l}\text { Чисто карбонатитовые } \\
\text { массивы с минималь- } \\
\text { ным количеством сили- } \\
\text { катных пород в виде ще- } \\
\text { лочных даек Лампрофи- } \\
\text { ры (преимущественно } \\
\text { ультраосновные дайки }\end{array}$ & 30 & \\
\hline & & Всего массивов & 347 & & 355 & \\
\hline
\end{tabular}

n- Количество массивов; в скобках после номера класса указано общее количество массивов в нем. 
На рисунке 2 представлено соотношение числа ассоциаций в провинциях и разницы возрастов между массивами в пределах провинции. Видно, что, во-первых, большинство провинций содержит не более трех классов, и, во-вторых, с увеличением длительности сушествования провинции (разницы в возрастах магматизма в разных массивах) количество представленных классов растет. Нам кажется, что это наблюдение отражает более сложное строение щелочных провинций, чем обычно считают. Поэтому нам представляется, что большой разброс возрастов массивов отражает совмешение в пространстве разных по сути провинций. Понятие щелочных провинций до сих пор проработано недостаточно, часто оно носит только географический характер и геологически не обосновано. Очевидно, что эта информация в базе нуждается в ревизии. Длительность магматизма видимо напрямую связана со сложностью строения массивов.

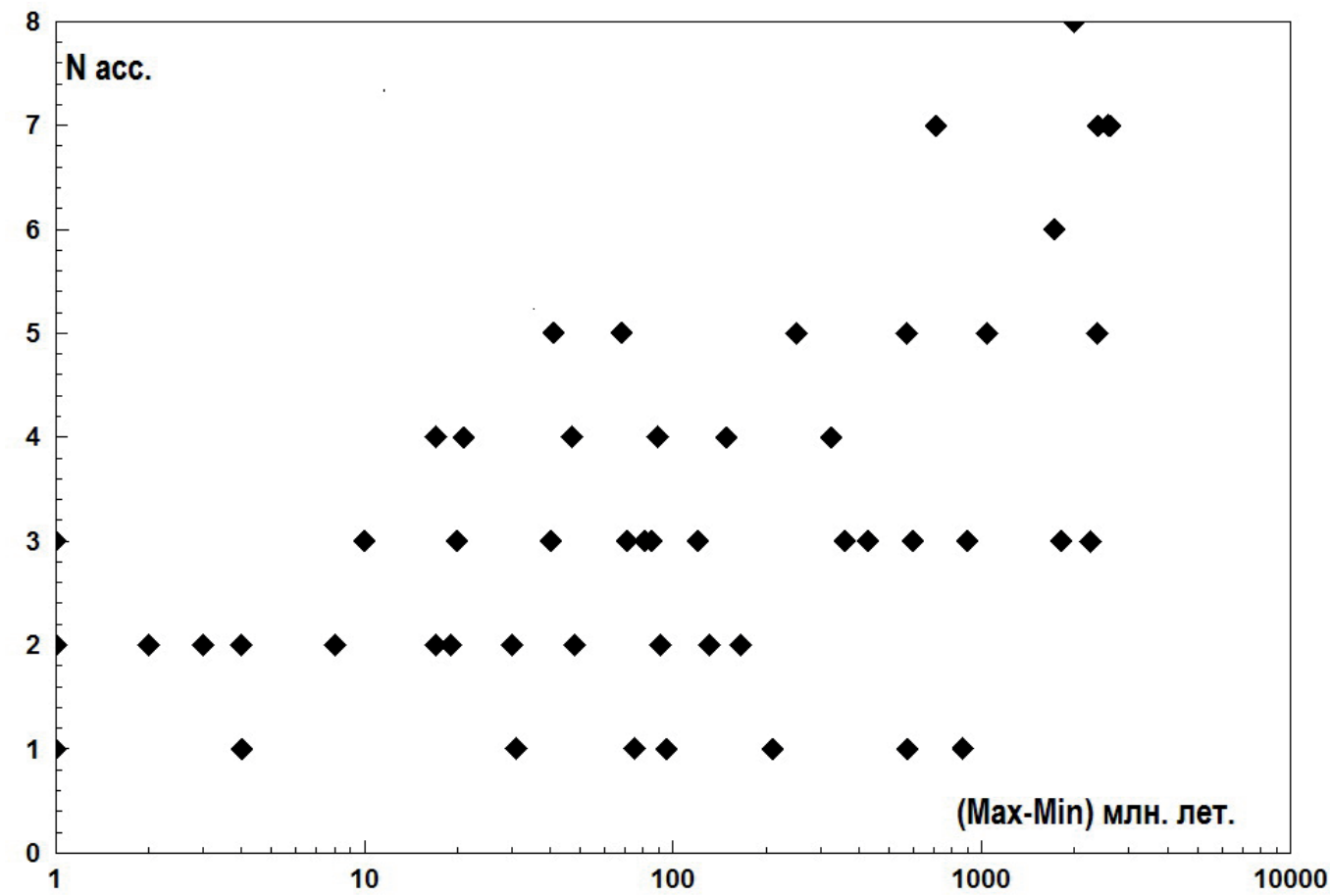

Рис. 2. График количества петрографических классов (N acc.), выделенных в провинции в зависимости от длительности магматизма (Мах-Мин) в млн. лет.

На рисунках 3-4 представлены ряд схем щелочных провинций, в которых цифра у значка указавает на возраст в млн. лет. Пока не понятно, есть ли закономерности в расположении массивов разного возраста в пределах провинции, но в ряде провинций (например Индии) линейность в изменении возраста массивов вдоль провинции отмечена на рисунке 3 .

Для карбонатитовых провинций Южной Америки наблюдается совмещение сильно различающихся по возрастам массивов. Видимо с этим связана крайне высокая гетерогенность по петрохимическим типам массивов. В этом случае мы наблюдаем тектоническое совмещение разных провинций - молодых и древних с разным типом магматической специализации. Характерно, что провинции по разную сторонуот LIP существенно отличается по типу магматизма. Это же наблюдение подтверждается при анализе щелочных провинци Сибири. Уджинская и Маймеча Котуйская провинции достаточно близки друг другу. В тоже время сильно отличается от них Чадобецкий массив на юге. В пределах Маймеча-Котуйской провинции можно выделить две области с разным типом магматизма. Северная - оливинит-мелилититовая (1-2 й класс) и южная - мельтейгит-ийолитсиенитовая (3-4 классы).

Указанные примеры позволяют говорить о преимущественно гомогенном строении провинций. Отмеченные примеры гетерогенности типов магматизма скорее отвечают линейному тренду 
изменения, а не симметричному - центростремительному. Однако мы рассматриваем данные результаты как предварительные, поскольку для уверенных выводом необходима более точная оценка петрохимии массивов с учетом имеющихся аналитических данных.

Интересным вопросом является связь возраста щелочного магматизма с возрастом гигантских магматических провинций толеитовых базальтов (LIP). Как видно из схем, для ряда провинций (Сибирская, Парана), которые имеют близкий возраст и располагаются непосредственно на гра-

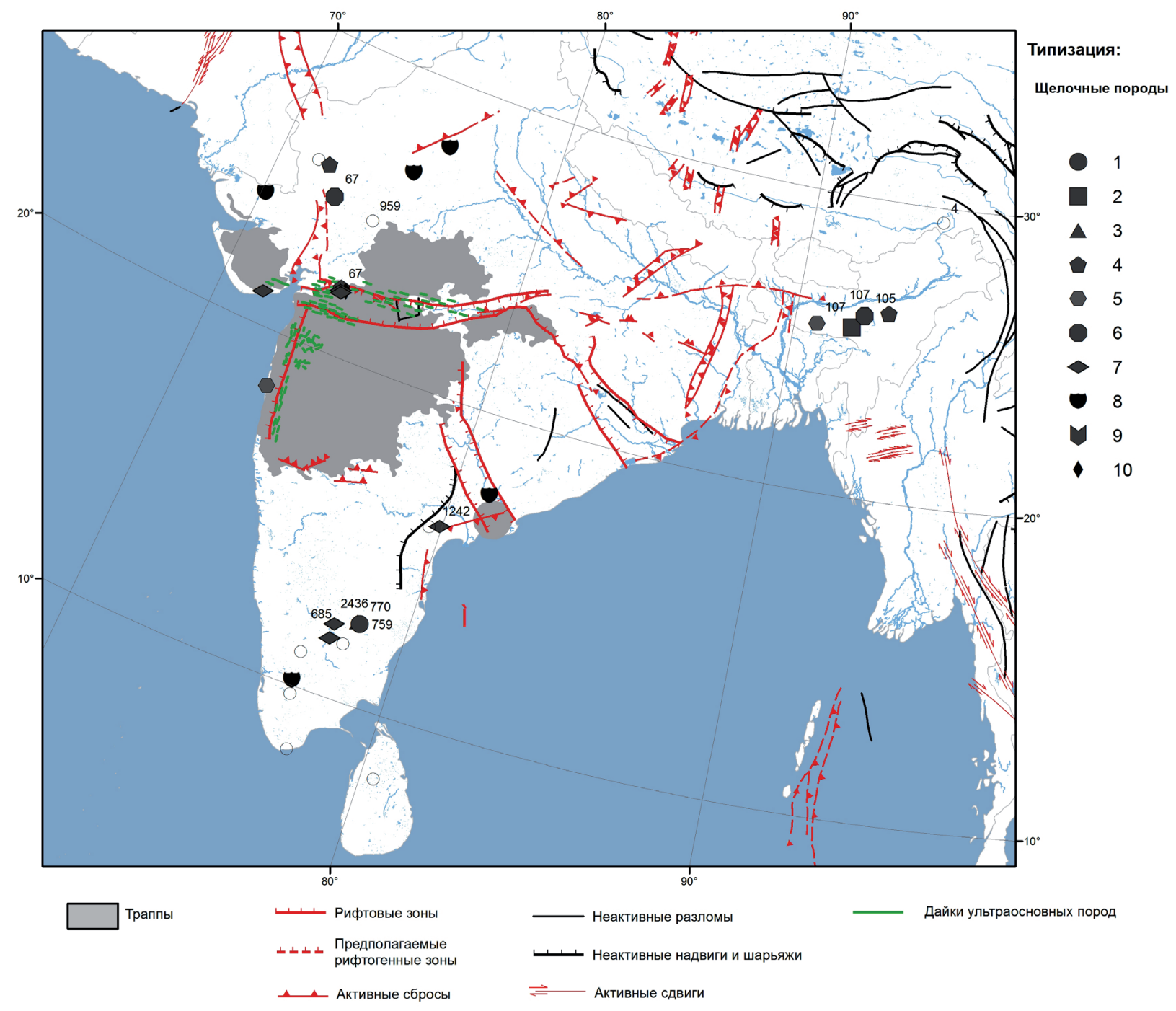

Рис. 3. Схема карбонатитового магматизма в области Деканского LIP провинции.

нице LIP, возраст массивов обычно моложе чем возраст базитового вулканизма. То есть первичная базитовая активность LIP обычно завершается щелочным магматизмом. Более сложные соотношения возрастов отмечены, например, в провинции Декан. Восточные участки Деканских лав ассоциируют с более древними щелочными массивами, а на границе основных проявлений LIP встречаются как более древние, так и более молодые проявления. В тоже время широкий интервал возрастов массивов в пределах провинции оставляет этот вопрос не до конца решенным. Интересно отметить, что положение разных провинций на границах LIP области пространственно выклядит как «диаметрально». То есть они располагаются не по всей границе области LIP, а локализуются в определенной ее части, и на противоположной строне LIP области проявляется симметричная провинция, правда с другим петрохимическим типом. Это наблюдение также является пока предварительным, но достаточно интересным, чтобы продолжить исследования в этом направлении. 


\section{Выводы}

Оценка петрохимического разнобразия щелочного магматизма в пределах провинций мира показала, что в основном, каждая из провинций петрохимически специализирована. В основном в них можно выделить не более 2-3 классов разных типов массивов. Редкие случаи совмещения в пределах провинций нескольких типов скорее всего связаны с совмещением разновозрастных проявлений магматизма связанных с различными плюмовыми источниками.

Зональность провинций носит преимущественно линейный характер. Что свидетельствует о гомогенности плюмового источника в течении достаточно длительного времени.

Связи плюмого и LIP магматизма подчеркиваются близким возрастом молодых проявлений магматизма, в то же время щелочной магматизм в основном завершает толеитовый и характеризуется более широким интервалом возрастов, что делает эту связь менее определнной.

\section{Благодарности}

Разработка ГИС проектов по щелочным провинциям Мира в данной работе финансировалась за счет государственного задания ГГМ РАН по теме №0140-2018-0003.

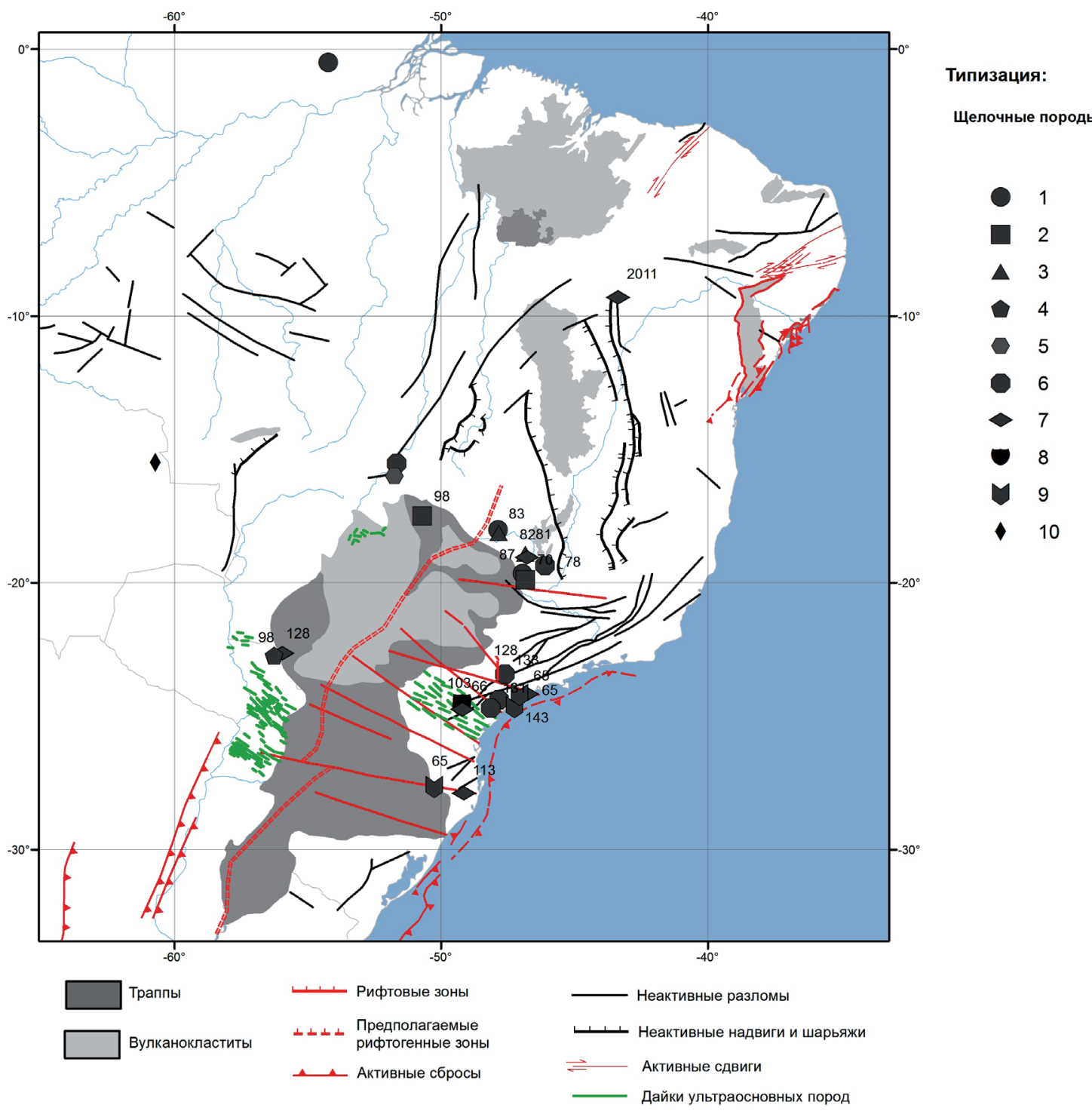

Рис. 4. Схема карбонатитового магматизма в области LIP провинции Парана. 


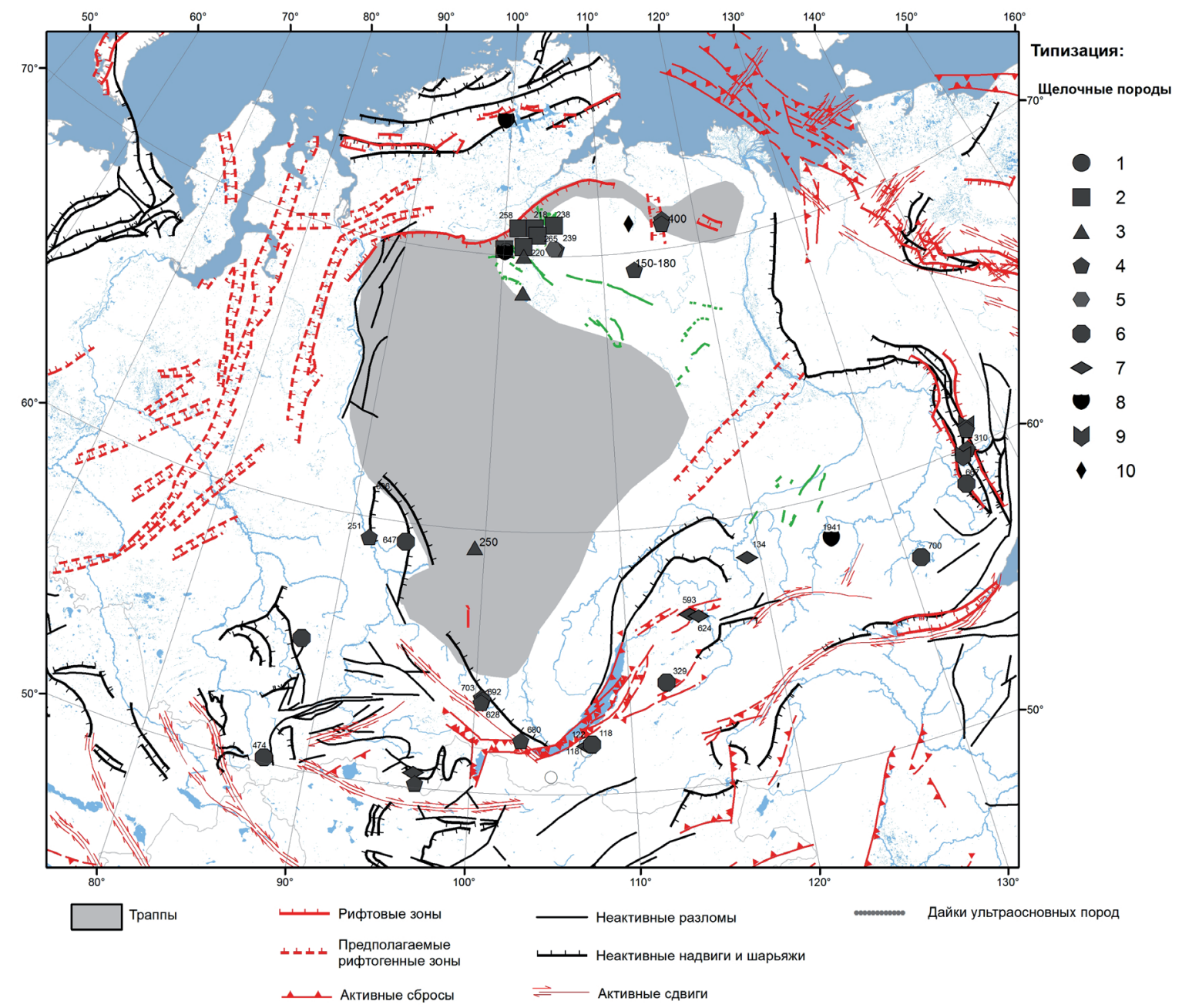

Рис. 5. Схема карбонатитового магматизма в области Сибирской LIP провинции.

\section{Литература}

1. Бородии Л.С., Лапин А.В., Харченко А.Г. Редкометальные камафориты // М.: Наука, 1973. 176 с.

2. Asavin A.M. Types of carbonatite and relative associated silicate rocks groups - by re-analysisis of the Database Woolley and Kjarsgaard // Proceedings of XXXII International Conference on Alkaline Magmatism of the Earth and Related Strategic Metal Deposits. Proceedings of XXXII International Conference. Apatity 7-14 August 2015, M.: GEOKHI RAS, 2015. 158 pp. - I 2015. P.13-17 SBN 978-5-905049-10-1 http://alkaline.web.ru/2015/.

3. Woolley Alan R. Igneous silicate rocks associated with carbonatites: their diversity, relative abundances and implications for carbonatite genesis // Per. Mineral. 2003. V .72. Spec. Issue: Eurocarb. P. 9-17.

4. Woolley Alan R., Bruce A. Kjarsgaard. Paragenetic types of carbonatite as indicated by the diversity and relative abundances of associated silicate rocks: evidence from a global database // The Canadian Mineralogist. 2008. V. 46. P. 741-752.

5. Woolley A.R., Kjarsgaard B.A. Book Review // Journal of petrology. 2009. V. 50. N. 1. P. 195-196. 